\title{
EFFICIENCY ACROSS HOSPITALS IN BANGLADESH: RESULTS FROM STOCHASTIC FRONTIER ANALYSIS
}

\author{
Sharmeen Mobin Bhuiyan ${ }^{1}$ \\ Nasrin Sultana ${ }^{2}$
}

\begin{abstract}
The health sector of Bangladesh achieved many of its goals. The sector, however, faces challenges. One major challenge is low efficiency. In a resourcepoor country, inefficiency leads to the waste of available resources widening the financing gap of the health sector. A technically efficient production unit produces a large amount of output with a given amount of inputs using a given state of technology. Technical efficiency of the district hospitals in Bangladesh is measured using the secondary source of data applying stochastic frontier analysis. Results show that the efficiency of some facilities is quite low and there is a mismatch of utilization rate and efficiency levels of the district hospitals. Measures like reducing absenteeism, increasing healthcare demand, and ensuring proper functioning of all inputs should be taken to enhance the efficiency and utilization of the district hospitals.
\end{abstract}

Keywords: efficiency, utilization, Stochastic Frontier Analysis (SFA), District hospital, parametric technique.

\section{Introduction}

The achievements health sector of Bangladesh is now a well-known fact. The sector, given the widespread challenges, achieved many of its goals. Achievements in reducing maternal, infant, and under-5 mortality rates, increased vaccination coverage, higher life expectancy at birth were attained despite only 2.37 current health expenditure as a percent of GDP (World Bank, 2019).

The sector, however, faces challenges that bar it from realizing improvements in some other health indicators. Among them, one major challenge is low

\footnotetext{
${ }^{1}$ Sharmeen Mobin Bhuiyan, PhD is Professor, Institute of Health Economics, University of Dhaka. Email: sharmeenmbhuiyan@gmail.com

2 Nasrin Sulatana, $\mathrm{PhD}$ is Professor, Institute of Health Economics, university of Dhaka. Email: nasrin865@hotmail.com 
efficiency. In a resource-poor country, inefficiency leads to the waste of available resources widening the financing gap of the health sector. Therefore, one major objective of the health sector is to ensure the highest levels of efficiency in resource use to reduce the financing gap and achieve the targeted goals. Extensive literature is there on the technical efficiency of health care facilities. These works show that the most widely used method for measuring efficiency in data envelopment analysis (DEA) and stochastic frontier analysis (SFA). These studies mostly involve developed countries. However, there is a dearth of literature on the technical efficiency measures done in developing countries. Only a very few have examined this issue in Bangladesh. One study by Walker (2006) estimated the efficiency of vaccination services in Dhaka City and primary health care in rural Bangladesh using SFA. The results show that these services are being rendered inefficiently with scope for further improvements.

The paper aims to analyse the levels of technical efficiency of the district hospitals in Bangladesh using the secondary source of data, the Health Bulletin (2017), applying stochastic frontier analysis. The levels of technical inefficiency will reveal the extent to which the sector can further improve its performances with the currently available resources and assist policymakers and managers of hospitals to adopt measures to reduce waste and enhance efficiency. The findings are expected to be beneficial to the policymakers and health researchers. The paper is organized into seven sections. After introductions, the second section portrays the method of analysis, data, and variables. The sections that follow are a review of the Literature: application of Stochastic Frontier Analysis (SFA), estimation of technical efficiency: results of SFA, comparison between utilization rate and efficiency score, discussion and finally concluding remarks.

\section{Method of Analysis, Data and Variable}

\section{Method of Analysis}

According to standard microeconomic theories, efficiency has three levels: technical efficiency, production efficiency, and allocative efficiency. A technically efficient firm or production unit produces a large amount of output with a given amount of inputs or produces a given output with a low quantity of inputs using a given state of technology. The highest production efficiency refers to producing goods and services with the optimal combination of inputs to produce maximum output at the minimum cost. Maximum allocative efficiency 
is concerned about what balance of outputs is to be produced. Maximum allocative efficiency of resource use is determined at the point of intersection of demand and supply curve in a competitive market. That is to say, allocative efficiency is maximum when producers' revenue and consumers' satisfaction are both highest. (Henderson \& Quandt, 1980).

There are different methods to measure economic efficiency, namely, ratio analysis, Pabon Lasso model, Data Envelopment Analysis (DEA), Stochastic Frontier Analysis (SFA). This paper aims to use the Stochastic Frontier Analysis method to measure the technical efficiency of all the district hospitals in Bangladesh. Stochastic Frontier Analysis (SFA) is a parametric method that has the advantage of allowing noise in measuring inefficiency. The method requires a pre-specified functional form of production, cost, or profit. Stochastic Frontier Analysis originated with two papers: Meeusen and van den Broeck (June, 1977) and Aigner, Lovell, and Schmidt (July, 1977). A third paper by Battese and Corra (1977) came at the end of the same year. The model can be expressed as:

$$
\mathrm{Y}=\mathrm{f}(\mathrm{x} ; \beta) \cdot \exp \left\{\varepsilon_{\mathrm{i}}\right\}
$$

Where $\mathrm{y}$ is scalar output, $\mathrm{x}$ is a vector of inputs, $\beta$ is a technology parameter, and $\varepsilon_{\mathrm{i}}$ is a composed error term (v-u). The first error component $\mathrm{v} \sim \mathrm{N}\left(0, \sigma_{v}^{2}\right)$ is intended to capture the effects of statistical noise, and the second error component $u \geq 0$ is intended to capture the effects of technical inefficiency. Thus, producers operate on or beneath their stochastic production frontier, as $u=0$ or $\mathrm{u}>0$. Meeusen and van den Broeck (1977) assigned an exponential distribution of $\mathrm{u}$, Battese and Corra assigned a half-normal distribution to $\mathrm{u}$, and Aigner et al. (1977)considered both distributions for $u$. Parameters to be estimated include $\beta \sigma_{v}^{2}$, and a variance parameter $\sigma^{2}$, associated with $\mathrm{u}$ (Kumbhakar and Lovell, 2000).

Battese and Coelli (1995) redefined the model and assumed a random error $\left(V_{i t}\right)$ and a nonnegative error term $\left(U_{i t}\right)$ representing the technical inefficiency. Here, $V_{i t}$ is assumed to be independent and identically distributed, i.i.d $N\left(0, \sigma^{2} v\right)$, and captures statistical noise, measurement error, and other random events that are beyond the firm's control. The non-negative error term $\left(U_{i t}\right)$ captures the inefficiency and is assumed to be i.i.d as truncations at zero of the $N\left(\mu, \sigma^{2} U\right)$. Also, $V_{i t}$ is assumed to be independent of the $U_{i t}$. The model may be formed as follows: 


$$
Y_{i t}=X_{i t} \beta+\left(V_{i t}-U_{i t}\right) \quad \mathrm{i}=1, \ldots . \mathrm{K} ; \mathrm{t}=1, \ldots \mathrm{T}
$$

where $Y_{i t}$ is the output of the $i_{t h}$ firm in the $t_{t h}$ time period; it $X$ is a $K \times 1$ vector of inputs of the $i_{t h}$ firm in the $t_{t h}$ time period; $\beta$ is a $K \times 1$ vector of unknown parameters; $V_{i t}$ and $U_{i t}$ are assumed to have normal and half-normal distribution, respectively.

Estimation of the SFA is applied in two steps. In the first step, a functional form for the relationship between inputs and outputs and a functional form for the probability distribution of the efficiency term are assumed. By estimating the slope parameters $(\beta)$, estimates for the frontier is obtained. In the second step, the actual cost is subtracted from predicted cost (i.e., c- $\mathrm{f}(\mathrm{y} ; \beta))$ and decomposes the remaining residual into a data error component (v) and an inefficiency component (u) for each firm. The method is illustrated in Figure 1.

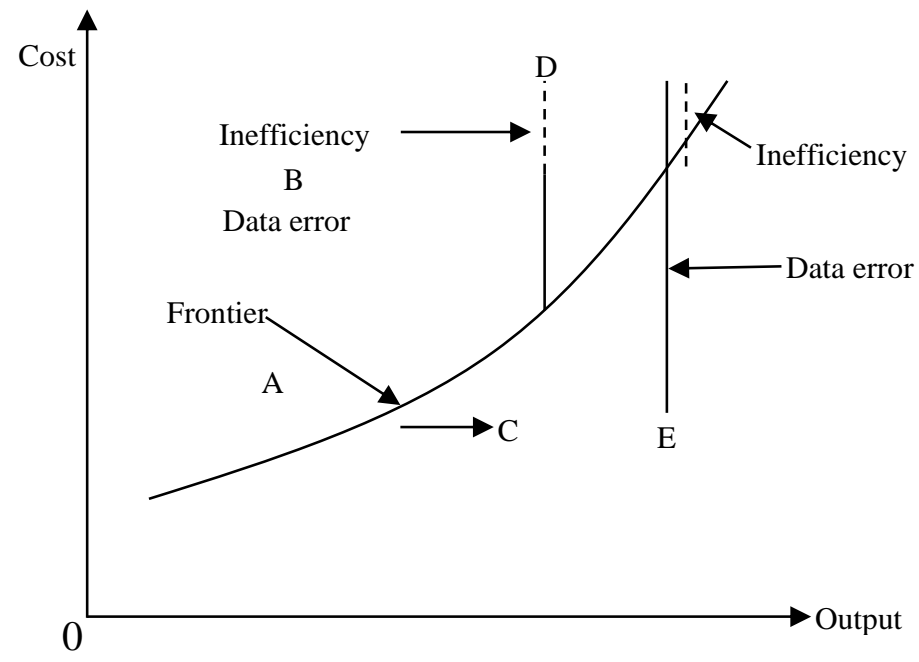

Source : Sarafidis (2002)

Figure 1: Stochastic Frontier Model

In Figure 1, for observations that lie above the frontier, the gap between each observation and the frontier is partially due to inefficiency with the remaining gap as the error in the measurement. For observations that lie below the frontier, the noise residual (v) is larger than the gap between the observation and the frontier in order to allow for inefficiency. This implies that none of the firms will be fully efficient (Sarafidis, 2002).

With the given input vector $\mathrm{x}_{\mathrm{i}}$, the potential output is defined as the maximal output obtained when there is no inefficiency effect on the production and 
formulated as follows as mentioned by Mailena, Shamsuddin, Radam, and Mohamed (2014):

$$
\mathrm{Y}^{*}=\exp \left(\mathrm{X}_{i} \beta+v_{i}\right)
$$

The estimated technical efficiency of the ith firm can be defined as the ratio of the observed output of the ith firms relative to the frontier output given the technology and is as follows:

$$
T E_{i}=\frac{Y}{Y^{*}}=\frac{\exp \left(X_{i} \beta+v_{i}-u_{i}\right.}{\exp \left(X_{i} \beta+v_{i}+u_{i}\right.}=\exp \left(-u_{i}\right)
$$

The technical efficiency score is between zero and one and a higher score indicates higher efficiency.

SFA has the advantage over any non-parametric techniques, such as DEA, as it provides statistical inference. However, as it uses a maximum likelihood estimation (MLE) method, in small samples it does not guarantee that the estimators will hold all the necessary statistical properties. Defining a standard sample size, therefore, is difficult. SFA assumes the functional form of the inefficiency effect. The most widely used distributions are the half-normal and exponential distribution. These distributions assume that there is a large number of relatively efficient firms and only a few firms are relatively inefficient, which may be impractical. In this case, both distributions would be inappropriate. This has led to the development of other distributions, such as the truncated-normal and the gamma distributions. The main criticism is that there is no a priori justification for selecting the distribution (Sarafidis, 2002).

A software named FRONTIER 4.1 was used for the analysis.

\section{Data and variable}

A secondary source of data was used for the analysis. Data from Health Bulletin (2017) were used for all 64 district hospitals (DHs). The SFA uses only one output. In a health care facility, there are two broad types of patients: inpatients and outpatients. Therefore, two models are used to measure efficiency. Model 1 considers number of outpatients ${ }^{1}$ as output variable and model 2 takes number of inpatients as output variable. The input variables used are number of doctors and nurses at the district hospitals (DHs) and the output variables used were the number of outpatient visits, inpatient visits, and emergency visits at the DHs. 


\section{Review of Literature: Application of Stochastic Frontier Analysis (SFA)}

Hamidi (2016) used SFA to measure the technical efficiency of government hospitals in Palestine. The number of beds, number of doctors, number of nurses, and the number of non-medical staff were the input variables, and the number of inpatients and outpatients were the output variable used for the analysis. The average technical efficiency found was around 55 percent and ranged from 28 to 91 percent. Doctors and nurses were identified as the most important inputs in contributing to efficiency. If hospitals increased all inputs by 1 percent, their production would be increased by 0.74 percent. He recommended increasing the numbers of providers and nurses to raise efficiency.

Purohit (2016), Kimsey (2009), and Farsi and Filippini (2004) examined the productive efficiency of hospitals using SFA employing cross-section and panel data. The findings recommended significant savings could be made through efficient use of resources. On average, large regional facilities were found to be the costliest ones. Farsi and Filippini (2004) found that one of the main sources of unnecessary expenses was related to long hospital stays in small hospitals. Purohit (2009) suggested that life expectancy in Punjab could be improved by correcting the factors that were influencing the low performance of the health system. It was recommended that raising the allocation of funds for the health workforce can improve efficiency.

Mateus, Joaquim, and Nunes (2015), Novignon and Lawanson (2014), and Adam (2012) assessed and compared hospital efficiency levels within and between countries using SFA with cross-section and panel data and OLS. The results revealed that in cross-sectional data SFA was not statistically different from OLS for one country while these were statistically different for other countries. As it gives robust results panel data were preferred over cross-section analysis (Mateus et al., 2015). Adam (2012) suggested that the differences in hospital costs were due to differences in country-specific productivity. It was also found that there exists a wide variation in the efficiency of health systems. Increasing health spending was found to be necessary provided that these resources are utilized efficiently.

\section{Estimation of Technical Efficiency: Results of SFA}

The total number of outpatients was $27,036,644$ in all DHs and it was the highest in Chittagong DH $(1,117,269)$ and the total number of inpatients was 2,245,191 in all DHs and it was also the highest in Chittagong DH $(91,441)$. 
Two models are used to measure efficiency. Model 1 considers number of outpatients and model 2 takes number of inpatients as output variable. The input variables used are number of doctors and nurses at the district hospitals (DHs).

Table 1: Efficiency score of the District Hospitals for Model 1 and Model 2

\begin{tabular}{|l|c|c|}
\hline \multicolumn{1}{|c|}{ Hospital } & Model 1 & Model 2 \\
\hline Bagerhat & 0.92 & 0.94 \\
\hline Bandarban & 0.70 & 0.63 \\
\hline Barguna & 0.63 & 0.63 \\
\hline Barisal & 0.68 & 0.66 \\
\hline Bhola & 0.93 & 0.97 \\
\hline Bogra & 0.90 & 0.77 \\
\hline Brahmanbaria & 0.85 & 0.71 \\
\hline Chandpur & 0.89 & 0.76 \\
\hline Chapai Nawabganj & 0.88 & 0.73 \\
\hline Chittagong & 0.90 & 0.93 \\
\hline Chuadanga & 0.87 & 0.76 \\
\hline Comilla & 0.92 & 0.92 \\
\hline Cox's Bazar & 0.92 & 0.98 \\
\hline Dhaka & 0.50 & 0.43 \\
\hline Dinajpur & 0.93 & 0.86 \\
\hline Faridpur & 0.76 & 0.79 \\
\hline Feni & 0.83 & 0.86 \\
\hline Gaibandha & 0.86 & 0.85 \\
\hline Gazipur & 0.85 & 0.64 \\
\hline Gopalganj & 0.76 & 0.65 \\
\hline Habiganj & 0.95 & 0.93 \\
\hline Jamalpur & 0.84 & 0.72 \\
\hline Jessore & 0.92 & 0.93 \\
\hline Jhalokati & 0.74 & 0.56 \\
\hline Jhenaidah & 0.91 & 0.97 \\
\hline Joypurhat & 0.85 & 0.74 \\
\hline Khagrachhari & 0.74 & 0.55 \\
\hline Khulna & 0.73 & 0.96 \\
\hline Kishoreganj & 0.96 & \\
\hline Kurigram & 0.94 & 0.85 \\
\hline Kushtia & 0.81 & \\
\hline & & \\
\hline
\end{tabular}




\begin{tabular}{|c|c|c|}
\hline Hospital & Model 1 & Model 2 \\
\hline Lalmonirhat & 0.75 & 0.73 \\
\hline Laxmipur & 0.84 & 0.74 \\
\hline Madaripur & 0.72 & 0.65 \\
\hline Magura & 0.71 & 0.58 \\
\hline Manikganj & 0.82 & 0.68 \\
\hline Meherpur & 0.86 & 0.64 \\
\hline Moulvibazar & 0.92 & 0.89 \\
\hline Munshiganj & 0.89 & 0.72 \\
\hline Mymensingh & 0.90 & 0.94 \\
\hline Naogaon & 0.94 & 0.91 \\
\hline Narail & 0.68 & 0.56 \\
\hline Narayanganj & 0.83 & 0.48 \\
\hline Narsingdi & 0.84 & 0.61 \\
\hline Natore & 0.92 & 0.81 \\
\hline Netrokona & 0.89 & 0.91 \\
\hline Nilphamari & 0.71 & 0.94 \\
\hline Noakhali & 0.87 & 0.82 \\
\hline Pabna & 0.94 & 0.97 \\
\hline Panchagarh & 0.85 & 0.81 \\
\hline Patuakhali & 0.71 & 0.80 \\
\hline Perojpur & 0.82 & 0.81 \\
\hline Rajbari & 0.69 & 0.69 \\
\hline Rajshahi & 0.83 & 0.75 \\
\hline Rangamati & 0.65 & 0.50 \\
\hline Rangpur & 0.73 & 0.80 \\
\hline Satkhira & 0.77 & 0.75 \\
\hline Shariatpur & 0.82 & 0.78 \\
\hline Sherpur & 0.90 & 0.77 \\
\hline Sirajganj & 0.86 & 0.72 \\
\hline Sunamganj & 0.96 & 0.94 \\
\hline Sylhet & 0.87 & 0.82 \\
\hline Tangail & 0.94 & 0.91 \\
\hline Thakurgaon & 0.73 & 0.95 \\
\hline Mean Efficiency Score & $\mathbf{0 . 8 3}$ & 0.78 \\
\hline$\gamma$ & 0.84 & 0.95 \\
\hline
\end{tabular}

Source: Results of SFA obtained by authors 
Estimates of the efficiency of the district hospitals is shown in Figure 2. The average technical efficiency score is 83 percent and 78 percent for models 1 and 2, respectively. In model 1 , the efficiency scores vary from 0.5 to 0.96 , and in model 2 the variation ranges from 0.43 to 0.98 . None of the hospitals score full efficiency.

$\gamma \rightarrow 1$ implies more of the variation is attributed to inefficiency, and $\gamma \rightarrow 0$ implies more of the variation due to statistical noise. Results show that in model $1 \gamma$ is 0.84 indicating that 84 percent of the variation is due to the technical inefficiency and in model $2 \gamma$ is 0.95 demonstrating that 95 percent variation was caused by technical inefficiency.

Based on the level of performances as shown by the results of SFA, the DHs were categorized into three groups: the facilities with score 90 percent or above were ranked as high-performing, facilities with score 75 percent to less than 90 percent were ranked medium-performing, and facilities with a score below 75 percent were ranked low-performing DHs. Table 2 shows the performances of the survey DHs.

Table 2: Performance rank of the District Hospitals for both model 1 and model 2

\begin{tabular}{|c|c|c|c|c|c|}
\hline Rank & $\begin{array}{c}\text { Name of District } \\
\text { Hospitals }\end{array}$ & $\begin{array}{l}\text { Model 1 } \\
\text { efficiency } \\
\text { scores } \\
\end{array}$ & Rank & $\begin{array}{c}\text { Name of District } \\
\text { Hospitals }\end{array}$ & $\begin{array}{c}\text { Model } 2 \\
\text { efficiency } \\
\text { scores }\end{array}$ \\
\hline \multirow{20}{*}{$\begin{array}{c}\text { High } \\
\text { performing } \\
\text { DHs }\end{array}$} & Bagerhat & 0.92 & \multirow{17}{*}{$\begin{array}{c}\text { High } \\
\text { performing } \\
\text { DHs }\end{array}$} & Bagerhat & 0.94 \\
\hline & Kishoreganj & 0.96 & & Cox's Bazar & 0.98 \\
\hline & Sunamganj & 0.96 & & Pabna & 0.97 \\
\hline & Habiganj & 0.95 & & Jhenaidah & 0.97 \\
\hline & Tangail & 0.94 & & Bhola & 0.97 \\
\hline & Kurigram & 0.94 & & Kishoreganj & 0.96 \\
\hline & Pabna & 0.94 & & Thakurgaon & 0.95 \\
\hline & Naogaon & 0.94 & & Sunamganj & 0.94 \\
\hline & Dinajpur & 0.93 & & Nilphamari & 0.94 \\
\hline & Bhola & 0.93 & & Mymensingh & 0.94 \\
\hline & Natore & 0.92 & & Chittagong & 0.93 \\
\hline & Cox's Bazar & 0.92 & & Jessore & 0.93 \\
\hline & Moulvibazar & 0.92 & & Habiganj & 0.93 \\
\hline & Jessore & 0.92 & & Comilla & 0.92 \\
\hline & Comilla & 0.92 & & Netrokona & 0.91 \\
\hline & Jhenaidah & 0.91 & & Naogaon & 0.91 \\
\hline & Sherpur & 0.90 & & Tangail & 0.91 \\
\hline & Chittagong & 0.90 & \multirow{6}{*}{$\begin{array}{c}\text { Medium } \\
\text { Performing } \\
\text { DHs }\end{array}$} & Moulvibazar & 0.89 \\
\hline & Bogra & 0.90 & & Kurigram & 0.88 \\
\hline & Mymensingh & 0.90 & & Feni & 0.86 \\
\hline \multirow{3}{*}{$\begin{array}{c}\text { Medium } \\
\text { Performing } \\
\text { DHs }\end{array}$} & Netrokona & 0.89 & & Dinajpur & 0.86 \\
\hline & Chandpur & 0.89 & & Kushtia & 0.85 \\
\hline & Munshiganj & 0.89 & & Gaibandha & 0.85 \\
\hline
\end{tabular}




\begin{tabular}{|c|c|c|c|c|c|}
\hline Rank & $\begin{array}{c}\text { Name of District } \\
\text { Hospitals }\end{array}$ & $\begin{array}{c}\begin{array}{c}\text { Model 1 } \\
\text { efficiency } \\
\text { scores }\end{array} \\
\end{array}$ & Rank & $\begin{array}{c}\text { Name of District } \\
\text { Hospitals }\end{array}$ & \begin{tabular}{|c|}
$\begin{array}{c}\text { Model 2 } \\
\text { efficiency } \\
\text { scores }\end{array}$ \\
\end{tabular} \\
\hline & Chapai Nawabganj & 0.88 & & Sylhet & 0.82 \\
\hline & Noakhali & 0.87 & & Noakhali & 0.82 \\
\hline & Chuadanga & 0.87 & & Panchagarh & 0.81 \\
\hline & Sylhet & 0.87 & & Perojpur & 0.81 \\
\hline & Sirajganj & 0.86 & & Natore & 0.81 \\
\hline & Meherpur & 0.86 & & Patuakhali & 0.80 \\
\hline & Gaibandha & 0.86 & & Rangpur & 0.80 \\
\hline & Gazipur & 0.85 & & Faridpur & 0.79 \\
\hline & Joypurhat & 0.85 & & Shariatpur & 0.78 \\
\hline & Brahmanbaria & 0.85 & & Bogra & 0.77 \\
\hline & Panchagarh & 0.85 & & Khulna & 0.77 \\
\hline & Jamalpur & 0.84 & & Sherpur & 0.77 \\
\hline & Laxmipur & 0.84 & & Chandpur & 0.76 \\
\hline & Narsingdi & 0.84 & & Chuadanga & 0.76 \\
\hline & Narayanganj & 0.83 & & Rajshahi & 0.75 \\
\hline & Feni & 0.83 & & \begin{tabular}{|l} 
Satkhira \\
\end{tabular} & 0.75 \\
\hline & Rajshahi & 0.83 & Low & Joypurhat & 0.74 \\
\hline & Manikganj & 0.82 & Performing & Laxmipur & 0.74 \\
\hline & Perojpur & 0.82 & & Chapai Nawabganj & 0.73 \\
\hline & Shariatpur & 0.82 & & Lalmonirhat & 0.73 \\
\hline & Kushtia & 0.81 & & Jamalpur & 0.72 \\
\hline & Satkhira & 0.77 & & Sirajganj & 0.72 \\
\hline & Gopalganj & 0.76 & & Munshiganj & 0.72 \\
\hline & Faridpur & 0.76 & & Brahmanbaria & 0.71 \\
\hline & Lalmonirhat & 0.75 & & Rajbari & 0.69 \\
\hline Low & Jhalokati & 0.74 & & Manikganj & 0.68 \\
\hline Performing & \begin{tabular}{|l} 
Khagrachhari \\
\end{tabular} & 0.74 & & Barisal & 0.66 \\
\hline & Rangpur & 0.73 & & Madaripur & 0.65 \\
\hline & Thakurgaon & 0.73 & & Gopalganj & 0.65 \\
\hline & Khulna & 0.73 & & Meherpur & 0.64 \\
\hline & Madaripur & 0.72 & & Gazipur & 0.64 \\
\hline & Magura & 0.71 & & Bandarban & 0.63 \\
\hline & Patuakhali & 0.71 & & Barguna & 0.63 \\
\hline & Nilphamari & 0.71 & & Narsingdi & 0.61 \\
\hline & Bandarban & 0.70 & & Magura & 0.58 \\
\hline & Rajbari & 0.69 & & Jhalokati & 0.56 \\
\hline & Narail & 0.68 & & Narail & 0.56 \\
\hline & Barisal & 0.68 & & \begin{tabular}{|l|} 
Khagrachhari \\
\end{tabular} & 0.55 \\
\hline & Rangamati & 0.65 & & Rangamati & 0.50 \\
\hline & Barguna & 0.63 & & Narayanganj & 0.48 \\
\hline & Dhaka & 0.50 & & Dhaka & 0.43 \\
\hline
\end{tabular}

Source: Results of SFA obtained by authors 
Out of 64 DHs 20 DHs are high performing when number of outpatients are considered as output variable in model 1, and 17 are high performing in model 2. Bagerhat DH ranks the highest in both the models. 28 DHs and 22 DHs rank medium in model 1 and model 2, respectively. In the low-ranking category, there are 16 DHs in model 1 and 25 DHs in model 2. It is evident from the result that in model 2, where the number of inpatients was considered as output variable the majority of the DHs performs at a lower level than that of model 2. This is because the number of outpatients is significantly higher than the number of inpatients in DHs.

\section{Comparison between Utilization Rate and Efficiency Score}

To achieve the goals of the health sector the issues of the utilization of services and efficient use of available resources to maximize output should be investigated. The average relative utilization rate is defined as the number of total visits or the total number of patients as a proportion of the population (Table 2). The total number of patients comprise outpatients only as the efficiency is compared to model 1 only with variable output is the outpatient number.

On average the utilization rate was only 20.39 percent. However, the rate is highest in Bandarban (36.45\%) but quite low in Barguna (10.13 percent) followed by Nilphamari (10.80). The DHs were ranked by the utilization rate. The facilities with 30 percent and above were ranked as high, those with from 20 percent to less than 30 percent ranked medium, and those with less than 20 percent as low and the efficiency levels were ranked using the same ranking criteria in Table 1 using the model 1 . Model 1 uses outpatient variable which is significantly greater than the inpatient number used in model 2. Table 3 indicates that efficiency ranks do not match with the utilization ranks for most facilities. Three DHs exist which show high efficiency at a low utilization rate: Comilla, Mymensingh and, Naogaon. One of the objectives of the public health sector is to attain a higher level of utilization even at the cost of efficiency. The three aforementioned facilities achieved the efficiency objective but not the utilization objective. Only Kishoreganj achieved both objectives of high efficiency and high utilization rate. Twelve of the facilities ranked low in both the efficiency and utilization scores. 
Table 3: Comparison between utilization rate and efficiency scores of the DHs

\begin{tabular}{|c|c|c|c|c|}
\hline Name of DH & $\begin{array}{l}\text { Utilization } \\
\text { rate }^{*}\end{array}$ & $\begin{array}{c}\text { Rank using } \\
\text { Utilization } \\
\text { rate }\end{array}$ & $\begin{array}{l}\text { Efficiency } \\
\text { model 1** }\end{array}$ & $\begin{array}{c}\text { Rank using } \\
\text { Efficiency first } \\
\text { input category }\end{array}$ \\
\hline Bagerhat & 27.26 & Medium & 0.92 & High \\
\hline Bandarban & 36.45 & High & 0.70 & Low \\
\hline Barguna & 10.13 & Low & 0.63 & Low \\
\hline Barisal & 13.11 & Low & 0.68 & Low \\
\hline Bhola & 20.95 & Medium & 0.93 & High \\
\hline Bogra & 22.14 & Medium & 0.90 & High \\
\hline Brahmanbaria & 13.07 & Low & 0.85 & Medium \\
\hline Chandpur & 19.04 & Low & 0.89 & Medium \\
\hline Chapai Nawabganj & 16.70 & Low & 0.88 & Medium \\
\hline Chittagong & 21.26 & Medium & 0.90 & High \\
\hline Chuadanga & 22.72 & Medium & 0.87 & Medium \\
\hline Comilla & 17.42 & Low & 0.92 & High \\
\hline Cox's Bazar & 27.09 & medium & 0.92 & High \\
\hline Dhaka & 19.80 & Low & 0.50 & Low \\
\hline Dinajpur & 26.17 & medium & 0.93 & High \\
\hline Faridpur & 19.18 & Low & 0.76 & Medium \\
\hline Feni & 21.97 & medium & 0.83 & Medium \\
\hline Gaibandha & 12.10 & Low & 0.86 & Medium \\
\hline Gazipur & 13.61 & Low & 0.85 & Medium \\
\hline Gopalganj & 25.33 & medium & 0.76 & Medium \\
\hline Habiganj & 26.04 & medium & 0.95 & High \\
\hline Jamalpur & 15.56 & Low & 0.84 & Medium \\
\hline Jessore & 22.80 & medium & 0.92 & High \\
\hline Jhalokati & 18.97 & Low & 0.74 & Low \\
\hline Jhenaidah & 21.27 & medium & 0.91 & High \\
\hline Joypurhat & 28.50 & medium & 0.85 & Medium \\
\hline Khagrachhari & 26.80 & medium & 0.74 & Low \\
\hline Khulna & 24.47 & medium & 0.73 & Low \\
\hline Kishoreganj & 34.08 & High & 0.96 & High \\
\hline Kurigram & 20.74 & medium & 0.94 & High \\
\hline Kushtia & 16.93 & Low & 0.81 & Medium \\
\hline Lalmonirhat & 12.68 & Low & 0.75 & Medium \\
\hline Laxmipur & 14.63 & Low & 0.84 & Medium \\
\hline Madaripur & 14.13 & Low & 0.72 & Low \\
\hline Magura & 15.59 & Low & 0.71 & Low \\
\hline Manikganj & 25.80 & medium & 0.82 & Medium \\
\hline Meherpur & 30.51 & High & 0.86 & Medium \\
\hline Moulvibazar & 23.43 & medium & 0.92 & High \\
\hline Munshiganj & 31.58 & High & 0.89 & Medium \\
\hline
\end{tabular}




\begin{tabular}{|l|c|c|c|c|}
\hline Name of DH & $\begin{array}{c}\text { Utilization } \\
\text { rate }^{*}\end{array}$ & $\begin{array}{c}\text { Rank using } \\
\text { Utilization } \\
\text { rate }\end{array}$ & $\begin{array}{c}\text { Efficiency } \\
\text { model 1** }\end{array}$ & $\begin{array}{c}\text { Rank using } \\
\text { Efficiency first } \\
\text { input category }\end{array}$ \\
\hline Mymensingh & 18.20 & Low & 0.90 & High \\
\hline Naogaon & 19.38 & Low & 0.94 & High \\
\hline Narail & 15.86 & Low & 0.68 & Low \\
\hline Narayanganj & 13.00 & Low & 0.83 & Medium \\
\hline Narsingdi & 15.83 & Low & 0.84 & Medium \\
\hline Natore & 24.96 & medium & 0.92 & High \\
\hline Netrokona & 17.36 & Low & 0.89 & Medium \\
\hline Nilphamari & 10.80 & Low & 0.71 & Low \\
\hline Noakhali & 14.76 & Low & 0.87 & Medium \\
\hline Pabna & 25.53 & medium & 0.94 & High \\
\hline Panchagarh & 22.40 & Medium & 0.85 & Medium \\
\hline Patuakhali & 12.19 & Low & 0.71 & Low \\
\hline Perojpur & 21.13 & Medium & 0.82 & Medium \\
\hline Rajbari & 15.36 & Low & 0.69 & Low \\
\hline Rajshahi & 35.75 & High & 0.83 & Medium \\
\hline Rangamati & 24.72 & Medium & 0.65 & Low \\
\hline Rangpur & 15.20 & Low & 0.73 & Low \\
\hline Satkhira & 12.92 & Low & 0.77 & Medium \\
\hline Shariatpur & 22.51 & Medium & 0.82 & Medium \\
\hline Sherpur & 21.55 & Medium & 0.90 & High \\
\hline Sirajganj & 11.15 & Low & 0.86 & Medium \\
\hline Sunamganj & 29.14 & Medium & 0.96 & High \\
\hline Sylhet & 19.13 & Low & 0.87 & Medium \\
\hline Tangail & 23.87 & Medium & 0.94 & High \\
\hline Thakurgaon & 12.28 & Low & 0.73 & Low \\
\hline Source:Heath & $2017)$ & & & \\
\hline
\end{tabular}

Source: *Health Bulletin (2017) and ${ }^{* *}$ results of SFA obtained by author

\section{Discussion}

Most of the DHs falls in the medium efficiency category. In both models 1 and 2, Dhaka DH ranked low and the utilization rate is also very low (19.80). The reasons for Dhaka DH to score low are first, doctors and nurses prefer to stay in Dhaka which makes the number of inputs is very high. But compared to the number of inputs the level of utilization of services is low as compared to the high-performing DHs, and second, there are many specialized and other private clinics in Dhaka district makes it easily available for the patients to opt for them instead of the DH. The low-ranking DHs indicates that there is a misuse of resources and the DHs could produce more output given their current level of inputs. 
One of the major objectives of the public health sector is to achieve higher levels of utilization in line with high efficiency. Comparison between utilization rates and efficiency scores of the facilities clearly show that efficiency categories do not match with the utilization categories for many DHs. It was found that three DHs show high efficiency at the low utilization rate. These three DHs obtained efficiency objectives but not the utilization objective. The objective of the health sector is to achieve high efficiency at a high level of utilization so that higher equity is attained. Only one facility achieved both objectives: Kishoreganj.

\section{Conclusion and Recommendations}

In a resource-poor country like Bangladesh, maximizing efficiency is of dire importance. Attaining high levels of efficiency can reduce waste and release pressure on financing in the health sector. However, high efficiency does not always guarantee a high utilization rate. A prime concern of the public health sector is to increase coverage and increase utilization of the healthcare facilities. But high efficiency can be achieved even at a low level of utilization. But the objective of the sector is to achieve high efficiency at a high level of utilization. Results show that the efficiency of some facilities is quite low and there is a mismatch of utilization rate and efficiency levels of the DHs.

Steps should be taken to enhance the efficiency and utilization of the DHs. The recommendations that stem from the research are that absenteeism should be reduced as underutilization of the available resources would reduce efficiency and increase waste, surplus human resource can be transferred to other understaffed facilities, inputs present at the facility should be enabled to work properly, demand for healthcare services should be increased through awareness programs to increase utilization. The study has a few limitations. Inputs were assumed to be fully employed. The inclusion of absenteeism in the results would change the level of efficiency of some facilities.

\section{Reference}

Adam, P. B. (2012). A Comparative Study of Finland, Sweden, Denmark and Norway. University of Oslo, May 13, 2011. Retrieved from https://www.duo.uio.no/bitstream/handle/10852/ 30233/Master-Persson.pdf?sequence=4\&isAllowed=y (Accessed on October 29, 2018).

Aigner, D., Lovell, K., Schmidt, P. (1977). Formulation and estimation of Stochastic Frontier Production Function Models. Journal of Econometrics, 6(1977), 21-37.

Battese, G. E., \& Coelli, T. J. (1995). A Model for Technical Inefficiency Effects in a Stochastic Frontier Production Function for Panel Data. Empirical Economics, 20(3), 325-332. 
Battese, G. E., \& Corra G.S. (1977). Estimation of a Production Frontier Model: With Application to the Pastoral Zone of Eastern Australia. Australian Journal of agricultural Economics, 21(3), 169-79.

Farsi, M., \& Filippini, M. (2004). An analysis of efficiency and productivity in Swiss hospitals. Report, Swiss Federal Statistical Office. The University of York Discussion Paper 177. Retrieved from http://citeseerx.ist.psu.edu/viewdoc/download?doi=10.1.1.429.8586\&rep= rep1\&type=pdf (Accessed on January 11, 2019).

Hamidi, S. (2016). Measuring efficiency of governmental hospitals in Palestine using stochastic frontier analysis. Cost Effectiveness and Resource Allocation, 14(3), 1-12. Retrieved from http://creativecommons.org/licenses/by/4.0/. (Accessed on November 2, 2018).

Henderson, J. M., \& Quandt, R. E., (1980). Microeconomic Theory A Mathematical Approach. International Edition (3rd), (No. 04; HB171. 5, H4 1980.) Mexico, McGraw-Hill Inc.

Kimsey, L. G. (2009). How efficient are military hospitals? A comparison of technical efficiency using stochastic frontier analysis [Doctoral dissertation] University of Kentucky, Paper 743. Retrieved from. https://uknowledge.uky.edu/gradschool_diss/743/ (Accessed on April 4, 2019).

Kumbhakar, S. C., \& Lovell, C. A. K. (2000). Stochastic Frontier Analysis. Cambridge: Cambridge University Press.

Mailena, L., Shamsuddin, M. N., Radam, A., \& Mohamed, Z. (2014). Efficiency of rice farms and its determinants: Application of Stochastic Frontier Analysis. Trends in Applied research, 9(7), 360-371.

Mateus, C., Joaquim, I., \& Nunes, C. (2015). Measuring hospital efficiency-comparing four European countries. European Journal of Public Health, 25(1), 52-58.

Meeusen, W., \& Broeck J. van den (1977). Efficiency Estimation from Cobb-Douglas Production Functions with Composed Error. International Economic Review, 18(2), 435-44.

Ministry of Health and Family Welfare (MoHFW). (2017). Health Bulletin. Dhaka: Ministry for Health and Family Welfare, Government of Bangladesh.

Novignon, J., \& Lawanson, A. (2014). Efficiency of health systems in sub-Sahara Africa: a comparative analysis of time varying stochastic frontier models. Paper No. 56897, posted 10 November 2014 07:38 UTC. Paper prepared for the 19th African Econometric Society (AES) Conference in Addis Ababa. MPRA (Munich Personal RePEc Archive)

Purohit, B. C. (2009). Efficiency of Health care Sector at Sub-State Level in India: A Case of Punjab. Online Journal of Health and Allied Sciences, 8(3), 2, 1-6.

Purohit, B. C. (2016). Efficiency in Health care Sector in Tamil Nadu (India): An Exploratory Analysis. Online J Health Allied Scs.2016; 15(1), 1. Retrieved from http://www.ojhas.org/ issue57/2016-1-1.html (Accessed on December 12, 2019).

Sarafidis, V. (2002). An Assessment of Comparative Efficiency Measurement Techniques. Europe Economics, 16, 01-21.

Walker, D. G. (2006). Efficiency of Primary Health Care in Low and Middle-Income Countries: Case Studies from Bangladesh. Thesis Submitted to The University of London for Examination for The Degree of Doctor of Philosophy. https://researchonline.lshtm.ac.uk/id/ eprint/878721/ 1/430775.pdf (Accessed on January 13, 2019).

World Bank. (2019). The World Bank Group. https://data.worldbank.org/indicator/SH.XPD. CHEX.GD.ZS?locations=BD (Accessed on December 13, 2019). 